\title{
Molecular relaxation processes in genomic DNA from leaf tissues: A surface-enhanced Raman spectroscopic study
}

\author{
Cristina M. Muntean ${ }^{\mathrm{a}, *}$, Ioan Bratu ${ }^{\mathrm{a}}$ and Nicolae Leopold ${ }^{\mathrm{b}}$

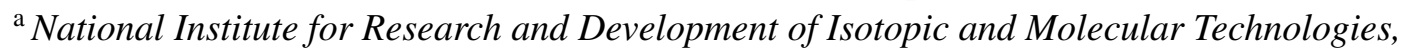 \\ Cluj-Napoca, Romania \\ ${ }^{\mathrm{b}}$ Faculty of Physics, Babeş-Bolyai University, Cluj-Napoca, Romania
}

\begin{abstract}
In this work the SERS total half bandwidths of six genomic DNAs from ex vitro-grown apple leaf tissues (Malus domestica Borkh., Fam. Rosaceae, cvs. Rebra, Goldrush, Florina, Romus 4, and the rootstocks M26, M9) and of five genomic DNAs from in vitro grown plants of Arnica montana (L.), Fam. Compositae, Astragalus peterfii (Jáv.), Fam. Fabaceae, strawberry (Fragaria x ananassa Duch.), Fam. Rosaceae, carnation (Dianthus caryophyllus L.), Fam. Caryophyllaceae, and Kalanchoe $x$ hybrida, Fam. Crassulaceae, respectively, have been measured.

We have shown that surface-enhanced Raman scattering can be used to study the fast subpicosecond dynamics of DNA in the proximity of a metallic surface. The dependencies of the total half bandwidths and of the global relaxation times, on DNA molecular subgroup structure and on the type of genomic DNA, are reported. It is shown that changes in the subpicosecond surface dynamics of molecular subgroups in genomic DNAs from leaf tissues can be monitored with surface-enhanced Raman spectroscopy.

In our study, the full widths at half-maximum (FWHMs) for the SERS bands of genomic DNAs from different leaf tissues, are typically in the wavenumber range from 15 to $30 \mathrm{~cm}^{-1}$ for data set 1 and from 13 to $42 \mathrm{~cm}^{-1}$ for data set 2. Besides, it can be observed that molecular relaxation processes studied in this work, have a global relaxation time smaller than $0.71 \mathrm{ps}$ and larger than $0.35 \mathrm{ps}$ (data set 1 ) and also varying between $0.25-0.82$ ps for data set 2 .

A comparison between different ranges of FT-Raman and SERS band parameters, respectively, of DNA extracted from leaf tissues is given.

We have found that the bands of DNA from Florina cultivar and Kalanchoe leaves, respectively, are suitable for the study of dynamical behaviour of molecular subgroups in nucleic acids extracted from different leaf tissues.
\end{abstract}

Keywords: Genomic DNA, plant species, leaf tissue, surface-enhanced Raman scattering, full width at half-maximum (FWHM), subpicosecond global relaxation time

\section{Introduction}

Studies of relaxation processes in liquids are valuable in providing information about the intermolecular interactions in condensed matter [3]. Raman and infrared spectroscopy offer the most significant information concerning the behaviour of a condensed system on the picosecond timescale [2,9].

Among the techniques available for the study of molecular motions in liquids, Raman scattering has the distinct advantage, that it enables simultaneous analyses of both reorientational and vibrational processes $([2,3,7,8]$ and references therein).

\footnotetext{
${ }^{*}$ Corresponding author: Cristina M. Muntean, National Institute for Research and Development of Isotopic and Molecular Technologies, P.O. 5, Box 700, R-400293 Cluj-Napoca, Romania. E-mail: cmuntean@itim-cj.ro.
} 
Particularly, vibrational relaxation plays a crucial role in many aspects of physics, chemistry and biology $([1,10]$ and references therein).

The macromolecular motion in fluids is generally too slow to be observed in the Raman time window that is accessible in the frequency domain. On contrary, the motion of molecular subgroups can be fast enough $[8,9,15]$.

A confocal Raman microspectroscopic study into the vibrational half bandwidths of molecular subgroups in calf-thymus DNA at $\mathrm{pH} 7$ and $\mathrm{pH} 3$, in the presence of $\mathrm{Na}^{+}, \mathrm{Ca}^{2+}$ and $\mathrm{Mg}^{2+}$ ions, respectively, was previously reported by us [5]. The bandwidths in the Raman spectra were sensitive to a dynamics active on a time scale ranging from 0.34 to 1.44 ps [5,7-9].

Also, the dependencies of the full widths at half-maximum (FWHMs) and of the global relaxation times on DNA molecular subgroup structure and on $\mathrm{pH}$ values, in the presence of $\mathrm{Mn}^{2+}$ ions, have been studied [7].

Molecular relaxation processes in calf-thymus DNA, in the presence of different concentrations of $\mathrm{Mn}^{2+}$ and $\mathrm{Na}^{+}$ions, respectively, were investigated by Raman spectroscopy $[6,9,13,14]$. The full widths at half-maximum (FWHMs) for the bands of DNA were typically in the wavenumber range from 9 to $33.5 \mathrm{~cm}^{-1}$. It could be observed that the molecular dynamics studied in this work, was characterized by a global relaxation time smaller than 1.18 ps and larger than 0.32 ps [6].

Also the subpicosecond dynamics of DNA subgroups, as a function of $\mathrm{Zn}^{2+}$ ions concentration [10] was presented. Monitoring the changes in the Raman full widths at half-maximum (FWHMs) and, correspondingly, in the global relaxation times of the molecular subgroups in DNA, upon varying the $\mathrm{Zn}^{2+}$ concentration, was of interest. It could be observed that the molecular relaxation processes studied in this work, had a global relaxation time smaller than 0.94 ps and larger than 0.21 ps $[9,10]$.

Besides, in a previous study of us, the full widths at half-maximum (FWHMs) of the SERS bands in genomic DNAs from in vitro-grown apple leaf tissues were typically in the wavenumber range from $14 \mathrm{~cm}^{-1}$ to $52 \mathrm{~cm}^{-1}$. Also, the molecular relaxation processes studied in that work, have a global relaxation time smaller than $0.76 \mathrm{ps}$ and larger than $0.20 \mathrm{ps}$ [9].

Also, vibrational relaxation after spectrally selective excitation within the $\mathrm{NH}$ stretching band of adenine-thymine base pairs, in DNA oligomers, was studied by subpicosecond infrared-pump/antiStokes Raman-probe spectroscopy [4].

In this paper the SERS total half bandwidths of six genomic DNAs from ex vitro-grown apple leaf tissues (Malus domestica Borkh., Fam. Rosaceae, cvs. Rebra, Goldrush, Florina, Romus 4, and the rootstocks M26, M9) and of five genomic DNAs from in vitro grown plants of Arnica montana (L.), Fam. Compositae, Astragalus peterfii (Jáv.), Fam. Fabaceae, strawberry (Fragaria x ananassa Duch.), Fam. Rosaceae, carnation (Dianthus caryophyllus L.), Fam. Caryophyllaceae, and Kalanchoe x hybrida, Fam. Crassulaceae, respectively, have been measured.

The dependencies of the total half bandwidths and of the global relaxation times, on DNA molecular subgroup structure and on the type of genomic plant DNA are reported.

It is shown that changes in the subpicosecond dynamics of molecular subgroups in genomic DNAs from different leaf tissues, in the proximity of a silver surface, can be monitored with surface-enhanced Raman spectroscopy (SERS).

Previously, a FT-Raman study of the (sub)picosecond dynamics in genomic DNA from plant tissues was also done by us [8] and is used for comparison in the present work [9]. 


\section{Experimental section}

Two sets of spectroscopic data were analyzed in this work.

The experimental details of the SERS spectra, obtained for genomic DNAs from different ex vitrogrown apple plant tissues, were given in [11]. Leaves sampled from apple trees grown in the field (Malus domestica Borkh., Fam. Rosaceae, cvs. Rebra, Goldrush, Florina, Romus 4 and the rootstocks M9 and M26) were the source material for the extraction of the genomic DNAs [11].

Besides, leaves from in vitro grown plant species represented the source material for extraction of the second set of genomic DNAs. These leaves were obtained from plants of Arnica montana (L.), Fam. Compositae, Astragalus peterfii (Jáv.), Fam. Fabaceae, strawberry (Fragaria x ananassa Duch.), Fam. Rosaceae, carnation (Dianthus caryophyllus L.), Fam. Caryophyllaceae, and Kalanchoe x hybrida, Fam. Crassulaceae, respectively [12]. SERS spectra of these genomic DNAs are presented elsewhere [12].

SERS spectral profiles in the region $200-1800 \mathrm{~cm}^{-1}$ of eight genomic DNAs, are presented in Fig. 1 [11].

A DeltaNu Advantage spectrometer (DeltaNu, Laramie, WY) equipped with a doubled frequency $\mathrm{Nd}$ :YAG laser, emitting at $532 \mathrm{~nm}$ and having a $45 \mathrm{~mW}$ laser power was used for recording the SERS spectra, at room temperature.

The band parameters (full widths at half-maximum-FWHMs and global relaxation times) were determined for both data sets.

For each band profile, an individual baseline was taken into account. FWHMs of the bands were obtained using SpectraCalc software. The FWHMs were evaluated from the half maximum SERS bands.



Fig. 1. SERS spectra of genomic DNAs from apple leaves sampled from the trees (cultivars and rootstocks), as labeled in the figure. Bottom, SERS spectrum of the silver colloid (blank spectrum). Spectra are presented at the same intensity scale expansion [11]. 


\section{Results and discussions}

Relating to molecular relaxation processes, Rakov developed one of the well-known procedures of obtaining the relaxation times and the activation energy [5-10,16].

In this approximation, the total half bandwidth of the depolarized Raman lines contains two contributions [5-9]:

- an intrinsic bandwidth, $\delta_{0}$, considered temperature independent in that time;

- another contribution $\Delta(T)$ which is temperature dependent.

The total half bandwidth can be written as:

$$
\Delta \nu_{1 / 2}=\delta_{0}+\Delta(T)=\delta_{0}+\frac{1}{\pi c \tau_{\mathrm{r}}} .
$$

The potential barrier against reorientation can be obtained as:

$$
\tau_{\mathrm{r}}=\tau_{0} \exp \left(\frac{U_{\text {or }}}{k T}\right)
$$

where $\tau_{0}$ is the period of the molecule oscillation around the equilibrium position and $U_{\text {or }}$ is the energy barrier or the activation energy $[5,6,9,10]$.

The Rakov relationship can be written as:

$$
\Delta \nu_{1 / 2}=\delta_{0}+\frac{1}{\pi c \tau_{0}} \exp \left(\frac{-U_{\text {or }}}{k T}\right)
$$

From the $\left(\Delta \nu_{1 / 2}-\delta_{0}\right) v s . \frac{10^{3}}{T}$ dependencies one can obtain $U_{\text {or }}$ as the slope of this linear dependence $[5-7,9]$.

The temperature "independent" part, due to the vibrational relaxation, $\delta_{\mathrm{v}}$, presents small temperature dependence, opposite to the one due to the reorientational relaxation.

For large molecules, in aqueous solutions, the vibrational contribution becomes important. From Raman measurements, using polarized light, it is possible to do the selection of these two contributions [5, $6,9,10]$. As a first approximation, one can assume, the existence of a global relaxation time, $\tau$, obtained from the total Raman half bandwidth. This band parameter can be related with the intrinsic parameters of the analyzed system through the relationship:

$$
\tau_{\mathrm{v}, 1 \mathrm{R}, 2 \mathrm{R}}=\frac{1}{\pi c \Delta \nu_{1 / 2}^{\mathrm{v}, 1 \mathrm{R}, 2 \mathrm{R}}},
$$

where the half bandwidth includes the vibrational $\left(\Delta \nu_{1 / 2}^{\mathrm{v}}\right)$ and rotational $\left(\Delta \nu_{1 / 2}^{1 \mathrm{R}, 2 \mathrm{R}}\right)$ contributions and $c$ is the velocity of light. $\Delta \nu_{1 / 2}^{1 R, 2 R}$ is obtained from IR and Raman bands, respectively [5-9].

The development of fast and accurate curve fitting programs allows the analysis of the vibrational spectra of complicated biological molecules, containing often more than 40 vibrational bands $([8,17]$ and references therein).

In this paper we will concentrate on the vibrational bandwidths. Only the relatively isolated nucleic acids vibrations will be considered [5,6,8,9]. A study into the SERS vibrational bandwidths and the 
corresponding global relaxation times of molecular subgroups in genomic DNAs from different leaf tissues, respectively, is of interest. This work follows a previous study of us, concerning SERS band parameters of genomic DNAs extracted from leaves of different in vitro-grown apple plants [9].

For the case of aqueous solutions of DNA molecules, we can suppose that the dominant relaxation mechanism is the vibrational one. The values of the global relaxation time suggest also the existence of a vibrational relaxation time, because the reorientational movement is much more slower for the DNA macromolecule in aqueous solution $[6,8]$.

The SERS band parameters for the vibrations near $755 \mathrm{~cm}^{-1}(\mathrm{dT}), 770 \mathrm{~cm}^{-1}(\mathrm{dC}), 1176 \mathrm{~cm}^{-1}$ (ring vibrations of dC), $1360 \mathrm{~cm}^{-1}(\mathrm{dT}, \mathrm{dA}), 1509 \mathrm{~cm}^{-1}(\mathrm{dA}), 1572 \mathrm{~cm}^{-1}(\mathrm{dG}, \mathrm{dA})$ and $1649 \mathrm{~cm}^{-1}$ [dT(C=O), $\left.\delta\left(\mathrm{H}_{2} \mathrm{O}\right)\right]$ characteristic to genomic DNAs from different ex vitro grown apple leaf tissues are summarized in Table 1 ([11] and references therein). Also, the SERS band parameters of the vibrations near $731 \mathrm{~cm}^{-1}$ (dA), $802 \mathrm{~cm}^{-1}$ (dC, backbone), $911 \mathrm{~cm}^{-1}$ (deoxyribose, backbone), $1173 \mathrm{~cm}^{-1}$ (ring vibrations of $\mathrm{dC}$ ),

Table 1

Total half bandwidths $\left(\mathrm{cm}^{-1}\right)$ of SERS vibrational markers and global relaxation times of molecular subgroups, in genomic DNA from different ex vitrogrown apple leaf tissues

\begin{tabular}{|c|c|c|}
\hline$\nu_{\max }\left(\mathrm{cm}^{-1}\right)\left(\right.$ tentative assignment $\left.{ }^{\mathrm{a}}[11]\right)$ & $\Delta \nu_{1 / 2}\left(\mathrm{~cm}^{-1}\right)$ & $\tau_{\text {SERS }}(\mathrm{ps})$ \\
\hline \multicolumn{3}{|l|}{ Rebra } \\
\hline $1509(\mathrm{dA})$ & 22 & 0.48 \\
\hline $1360(\mathrm{dT}, \mathrm{dA})$ & 22 & 0.48 \\
\hline 1176 (ring vibrations of $\mathrm{dC}$ ) & 23 & 0.46 \\
\hline $770(\mathrm{dC})$ & 23 & 0.46 \\
\hline 609 & 15 & 0.71 \\
\hline \multicolumn{3}{|l|}{ Goldrush } \\
\hline $1509(\mathrm{dA})$ & 24 & 0.44 \\
\hline $1360(\mathrm{dT}, \mathrm{dA})$ & 20 & 0.53 \\
\hline $769(\mathrm{dC})$ & 21 & 0.51 \\
\hline 610 & 15 & 0.71 \\
\hline \multicolumn{3}{|l|}{ Florina } \\
\hline $1649\left[\mathrm{dT}(\mathrm{C}=\mathrm{O}), \delta\left(\mathrm{H}_{2} \mathrm{O}\right)\right]$ & 17 & 0.62 \\
\hline $1572(\mathrm{dG}, \mathrm{dA})$ & 23 & 0.46 \\
\hline $1508(\mathrm{dA})$ & 22 & 0.48 \\
\hline $1359(\mathrm{dT}, \mathrm{dA})$ & 20 & 0.53 \\
\hline $769(\mathrm{dC})$ & 20 & 0.53 \\
\hline 610 & 16 & 0.66 \\
\hline \multicolumn{3}{|l|}{ M26 } \\
\hline $755(\mathrm{dT})$ & 21 & 0.51 \\
\hline 564 & 25 & 0.42 \\
\hline 485 & 30 & 0.35 \\
\hline \multicolumn{3}{|l|}{ Romus 4} \\
\hline 566 & 24 & 0.44 \\
\hline 486 & 28 & 0.38 \\
\hline \multicolumn{3}{|l|}{ M9 } \\
\hline 566 & 24 & 0.44 \\
\hline 487 & 30 & 0.35 \\
\hline
\end{tabular}

${ }^{a}$ Abbreviations: $\mathrm{dA}$ - deoxyadenosine; $\mathrm{dG}$ - deoxyguanosine; $\mathrm{dC}$ - deoxycytidine; $\mathrm{dT}$ - deoxythymidine. 
Table 2

Total half bandwidths $\left(\mathrm{cm}^{-1}\right)$ of SERS vibrational markers and global relaxation times of molecular subgroups, in genomic DNA from leaves of different in vitro grown plant species

\begin{tabular}{lll}
\hline$\nu_{\max }\left(\mathrm{cm}^{-1}\right)$ (tentative assignment $\left.{ }^{\mathrm{a}}[12]\right)$ & $\Delta \nu_{1 / 2}\left(\mathrm{~cm}^{-1}\right)$ & $\tau_{\text {SERS }}(\mathrm{ps})$ \\
\hline Arnica & 17 & \\
1620 [dT(C=O)] & $14^{*}$ & 0.62 \\
910 (Deoxyribose, backbone) & 20 & 0.76 \\
799 (dC, backbone) & & 0.53 \\
Astragalus & 19 & \\
1176 (Ring vibrations of dC) & 15 & 0.56 \\
909 (Deoxyribose, backbone) & & 0.71 \\
Fragaria & 23 & \\
1621 [dT(C=O)] & 26 & 0.46 \\
1173 (Ring vibrations of dC) & 16 & 0.41 \\
911 (Deoxyribose, backbone) & 23 & 0.66 \\
801 (dC, backbone) & & 0.46 \\
Dianthus & $42^{\#}$ & \\
1621 [dT(C=O)] & 13 & 0.25 \\
911 (Deoxyribose, backbone) & 27 & 0.82 \\
797 (dC, backbone) & 17 & 0.39 \\
731 (dA) & & 0.62 \\
Kalanchoe & 18.5 & \\
1626 [dT(C=O)] & 36 & 0.57 \\
1538 (dG, dA) & 24 & 0.29 \\
1444 (Deoxyribose, dCH $\left.{ }_{2}\right)$ & 41 & 0.44 \\
1381 (dT, dA) & 26 & 0.26 \\
1173 (Ring vibrations of dC) & 16 & 0.41 \\
911 (Deoxyribose, backbone) & 24 \\
802 (dC, backbone) & 17 \\
723 (dA) & & 0.66 \\
\hline
\end{tabular}

a Abbreviations: $\mathrm{dA}$ - deoxyadenosine; $\mathrm{dG}$ - deoxyguanosine; $\mathrm{dC}$ - deoxycytidine; dT - deoxythymidine.

${ }^{*}$ Low frequency side of the band was red, later on the respective profile was symmetrically analyzed.

\#High frequency side of the band was red, later on the respective profile was symmetrically analyzed.

$1381 \mathrm{~cm}^{-1}$ (dT, dA), $1444 \mathrm{~cm}^{-1}$ (deoxyribose, $\left.\mathrm{dCH}_{2}\right), 1538 \mathrm{~cm}^{-1}(\mathrm{dG}, \mathrm{dA})$ and $1621 \mathrm{~cm}^{-1}$ [dT(C=O)], characterizing genomic DNAs from different in vitro grown plant species are presented in Table 2 ([12] and references therein).

The full widths at half-maximum (FWHM) of the SERS bands in genomic DNAs from different ex vitro grown apple leaf tissues, are given for six samples in Table 1. Spectroscopic data of DNA from Idared and Romus 3 leaf tissues (Fig. 1), were not suitable for the investigation of nucleic acids' subpicosecond dynamics. Also, the FWHMs of surface-enhanced Raman bands of genomic DNAs from leaves of different in vitro grown plant species are presented for five samples in Table 2.

This parameter is typically in the wavenumber range from 15 to $30 \mathrm{~cm}^{-1}$ for data presented in Table 1 and from 13 to $42 \mathrm{~cm}^{-1}$ for data presented in Table 2. The limit wavenumber values belong in the first 
case to DNA from Rebra, Goldrush and M26, M9, respectively. In the second case, they belong to DNA from Dianthus. For some wavenumbers, the FWHMs were not possible to be read.

Besides, the global relaxation times were evaluated on the basis of Eq. (4). From the SERS vibrations around 755, 770, 1176, 1360, 1509, 1572 and $1649 \mathrm{~cm}^{-1}$ (see Table 1), it can be observed that the global relaxation times, for molecular subgroups in genomic DNA from different ex vitro grown apple leaf tissues, are slower than $0.44 \mathrm{ps}$ and faster than $0.62 \mathrm{ps}$. The best vibrational energy transfer process was obtained for the dA band at $1509 \mathrm{~cm}^{-1}$, in the case of DNA extracted from Goldrush cultivar (global relaxation time $0.44 \mathrm{ps}$ ) and the slowest dynamics was found for the band near $1649 \mathrm{~cm}^{-1}$ [dT(C=O), $\delta\left(\mathrm{H}_{2} \mathrm{O}\right)$ ], in the case of DNA extracted from Florina DNA (global relaxation time $0.62 \mathrm{ps}$ ).

Also, the bandwidths of the SERS vibrations around $731 \mathrm{~cm}^{-1}(\mathrm{dA}), 802 \mathrm{~cm}^{-1}$ (dC, backbone), $911 \mathrm{~cm}^{-1}$ (deoxyribose, backbone), $1173 \mathrm{~cm}^{-1}$ (ring vibrations of dC), $1381 \mathrm{~cm}^{-1}(\mathrm{dT}, \mathrm{dA}), 1444 \mathrm{~cm}^{-1}$ (deoxyribose, $\left.\mathrm{dCH}_{2}\right), 1538 \mathrm{~cm}^{-1}(\mathrm{dG}, \mathrm{dA})$ and $1621 \mathrm{~cm}^{-1}$ [dT(C=O)] of DNAs from different in vitro grown plant species (see Table 2) are sensitive to a dynamics active on a time scale from 0.25 to $0.82 \mathrm{ps}$.

Besides, the FT-Raman band parameters for the vibrations at $879 \mathrm{~cm}^{-1}$ (deoxyribose, dA), $1047 \mathrm{~cm}^{-1}$ (CO stretching C-O-P-O-C, dG), $1089 \mathrm{~cm}^{-1}\left(\mathrm{P}-\mathrm{O}\right.$ symmetric stretching of $\left.\mathrm{PO}_{2}^{-}\right), 1124 \mathrm{~cm}^{-1}(\mathrm{dA})$, $1272 \mathrm{~cm}^{-1}(\mathrm{dC}, \mathrm{dG}, \mathrm{dT}), 1276 \mathrm{~cm}^{-1}(\mathrm{dC}), 1455 \mathrm{~cm}^{-1}$ (deoxyribose, dA, dC, dT) and $1482 \mathrm{~cm}^{-1}(\mathrm{dG}$, dA) of genomic DNAs from leaf tissues were previously reported by us [8]. In that work, it could be observed that the molecular relaxation processes have a global relaxation time smaller than $1.36 \mathrm{ps}$ and larger than $0.46 \mathrm{ps}$.

For the cases of overlapped Raman profiles, only half of the total half bandwidth (FWHM), in the side where the bands were not superposed, was taken into account and later on it was multiplied by two.

We will analyze in the followings, data in Table 1.

The global relaxation time of the band near $755 \mathrm{~cm}^{-1}(\mathrm{dT})$ has the value $0.51 \mathrm{ps}$ and belongs to M26.

Referring to the $\mathrm{dC}$ residues vibration at $770 \mathrm{~cm}^{-1}$ the vibrational energy transfer processes are characterized by global relaxation times between $0.46-0.53$ ps. The smallest global relaxation time was found for DNA of Rebra, in the case of this band.

The global relaxation time of the band at $1176 \mathrm{~cm}^{-1}$ (ring vibrations of $\mathrm{dC}$ ) in the case of DNA from ex vitro grown Rebra cultivar was found to be $0.46 \mathrm{ps}$.

Previously, we have also been observed a global relaxation time of 0.45 ps for the profile near $1179 \mathrm{~cm}^{-1}$, in the case of DNA from in vitro grown Rebra cultivar [9].

Identical values of the SERS global relaxation times have been obtained for the band at $1360 \mathrm{~cm}^{-1}$ (dT, dA), in the case of genomic DNAs isolated from Goldrush and Florina leaf tissues, respectively (0.53 ps). Besides, a faster dynamics was also found for this band, in the case of Rebra cultivar (0.48 ps).

The global relaxation time of the band near $1509 \mathrm{~cm}^{-1}(\mathrm{dA})$ is in the range of $0.44-0.48 \mathrm{ps}$. The fastest dynamics of this band was detected for Goldrush DNA (global relaxation time $0.44 \mathrm{ps}$ ) and the slowest dynamics was observed for DNA from Rebra and Florina cultivars, respectively (identical global relaxation times $0.48 \mathrm{ps}$ ) (see Table 1 ).

Also, we have found a fast dynamics for the band near $1572 \mathrm{~cm}^{-1}(\mathrm{dG}, \mathrm{dA})$ of DNA from Florina cultivar (global relaxation time $0.46 \mathrm{ps}$ ).

In the case of DNA from Rebra cultivar, the global relaxation times corresponding to the bands near 1509 and $1360 \mathrm{~cm}^{-1}$ are identical $(0.48 \mathrm{ps})$. The same observation is valid for this cultivar in the case of profiles at 770 and $1176 \mathrm{~cm}^{-1}$, both characterizing $\mathrm{dC}$ residues (global relaxation times $0.46 \mathrm{ps}$ ).

We will also discuss data in Table 2 , in the next paragraphs.

Global relaxation times of $0.62 \mathrm{ps}$ have been found by us for the profile near $723 \mathrm{~cm}^{-1}$ (dA), in the case of DNA extracted from Dianthus and Kalanchoe cultivars, respectively. 
The $\mathrm{dC}$, backbone band profile near $802 \mathrm{~cm}^{-1}$, is characterized by global relaxation times in the subpicosecond range of $0.39-0.53$ ps. The fastest dynamics of this band was found for Dianthus DNA $(0.39 \mathrm{ps})$ and the slowest dynamics was detected in the case of DNA from Arnica (0.53 ps).

The global relaxation time characterizing the band near $911 \mathrm{~cm}^{-1}$ (deoxyribose, backbone) varied between $0.66-0.82 \mathrm{ps}$. The maximum value, corresponding to the slowest relaxation process belongs to the SERS band of DNA from Dianthus. The smallest global relaxation time $(0.66 \mathrm{ps})$ and the largest half bandwidth $\left(16 \mathrm{~cm}^{-1}\right)$, have been detected for the SERS band at $911 \mathrm{~cm}^{-1}$, in the case of DNAs extracted from Fragaria and Kalanchoe, respectively.

Referring to the $\mathrm{dC}$ ring vibration near $1173 \mathrm{~cm}^{-1}$, the vibrational energy transfer processes are characterized by global relaxation times ranging between $0.41-0.56 \mathrm{ps}$. The smallest global relaxation time was found for DNA from Fragaria and Kalanchoe, respectively. The slowest dynamics, characterizing this profile, was found for DNA from Astragalus.

The global relaxation times of the SERS bands near $1381 \mathrm{~cm}^{-1}(\mathrm{dT}, \mathrm{dA}), 1444 \mathrm{~cm}^{-1}$ (deoxyribose, $\left.\mathrm{dCH}_{2}\right)$ and $1538 \mathrm{~cm}^{-1}(\mathrm{dG}, \mathrm{dA})$ of DNA from Kalanchoe, have the values of $0.26,0.44$ and $0.29 \mathrm{ps}$, respectively.

Besides, vibrational energy transfer processes characterized by global relaxation times between 0.25 $0.62 \mathrm{ps}$ have been found by us for the band near $1620 \mathrm{~cm}^{-1}[\mathrm{dT}(\mathrm{C}=\mathrm{O})]$, in the case of DNA extracted from Dianthus (global relaxation time $0.25 \mathrm{ps}$ ), from Fragaria (global relaxation time $0.46 \mathrm{ps}$ ), from Kalanchoe (global relaxation time $0.57 \mathrm{ps}$ ) and from Arnica, respectively (global relaxation time $0.62 \mathrm{ps})$.

As a general observation, in the case of the first data set (see Table 1), we do not have overlapping bands leading to high FWHMs (e.g., $42 \mathrm{~cm}^{-1}$ ) as in the case of data presented in Table 2.

We have found that the bands of DNA from Florina cultivar and Kalanchoe, respectively, are suitable for the study of dynamical behaviour of molecular subgroups in nucleic acids extracted from different leaf tissues (see Tables 1 and 2).

Besides, a comparison between different ranges of the Raman band parameters, in the case of aqueous solution dynamics (FT-Raman) and surface dynamics (SERS) of DNA extracted from leaf tissues is given in Table 3.

The surface dynamics of molecular subgroups in plant DNA is more rapid than the solution dynamics of nucleic acids extracted from leaves, that is mobility is greater even in the case of interaction with a surface. An explanation of this observation might be, that in solution are possible to be present molecular associations, solvent interactions, etc., leading to a slower dynamics (a slower mobility). On the surface, the clusters are broken down and DNA is interacting only with the surface, having a higher mobility [9].

Table 3

Comparison between different ranges of the Raman band parameters, in the case of aqueous solution dynamics (FT-Raman) and surface dynamics (SERS) of DNA extracted from different leaf tissues

\begin{tabular}{lcc}
\hline DNA molecules & $\begin{array}{c}\text { FWHM range } \\
\Delta \nu\left(\mathrm{cm}^{-1}\right)\end{array}$ & $\begin{array}{c}\text { Global relaxation time range } \\
\tau(\mathrm{ps})\end{array}$ \\
\hline Genomic DNA from in vitro-grown plant species, FT-Raman study [8] & $7.8-23.1$ & $0.46-1.36$ \\
Genomic DNA from ex vitro-grown apple plants, SERS study & $15-30$ & $0.35-0.71$ \\
Genomic DNA from in vitro-grown plant species, SERS study & $13-42$ & $0.25-0.82$ \\
Genomic DNA from in vitro-grown apple plants, SERS study, time 1 [9] & $14-52$ & $0.20-0.76$ \\
Genomic DNA from in vitro-grown apple plants, SERS study, time 2 [9] & $14.5-23$ & $0.46-0.73$ \\
\hline
\end{tabular}




\section{Conclusions}

This work presents a surface-enhanced Raman spectroscopic study into the vibrational total half bandwidths of molecular subgroups in six genomic DNAs from leaves sampled from apple trees grown in the field (Malus domestica Borkh., Fam. Rosaceae, cvs. Rebra, Goldrush, Florina, Romus 4 and the rootstocks M9 and M26) and, also in five genomic DNAs from leaf tissues from in vitro grown plant species of Arnica montana (L.), Fam. Compositae, Astragalus peterfii (Jáv.), Fam. Fabaceae, strawberry (Fragaria $x$ ananassa Duch.), Fam. Rosaceae, carnation (Dianthus caryophyllus L.), Fam. Caryophyllaceae, and Kalanchoe $x$ hybrida, Fam. Crassulaceae, respectively. Besides, the corresponding global relaxation times have been derived.

We have shown that surface-enhanced Raman scattering can be used to study the fast subpicosecond dynamics of DNA from plant tissues in the proximity of a metallic surface.

SERS band parameters were obtained for vibrational modes including $755 \mathrm{~cm}^{-1}(\mathrm{dT}), 770 \mathrm{~cm}^{-1}(\mathrm{dC})$, $1176 \mathrm{~cm}^{-1}$ (ring vibrations of $\mathrm{dC}$ ), $1360 \mathrm{~cm}^{-1}(\mathrm{dT}, \mathrm{dA}), 1509 \mathrm{~cm}^{-1}(\mathrm{dA}), 1572 \mathrm{~cm}^{-1}(\mathrm{dG}, \mathrm{dA})$ and $1649 \mathrm{~cm}^{-1}\left[\mathrm{dT}(\mathrm{C}=\mathrm{O}), \delta\left(\mathrm{H}_{2} \mathrm{O}\right)\right]$, characteristic to genomic DNAs from different ex vitro grown apple leaf tissues ([11] and references therein) and, also including vibrations at $731 \mathrm{~cm}^{-1}(\mathrm{dA}), 802 \mathrm{~cm}^{-1}$ (dC, backbone), $911 \mathrm{~cm}^{-1}$ (deoxyribose, backbone), $1173 \mathrm{~cm}^{-1}$ (ring vibrations of $\mathrm{dC}$ ), $1381 \mathrm{~cm}^{-1}$ (dT, dA), $1444 \mathrm{~cm}^{-1}$ (deoxyribose, $\mathrm{dCH}_{2}$ ), $1538 \mathrm{~cm}^{-1}\left(\mathrm{dG}, \mathrm{dA}\right.$ ) and $1621 \mathrm{~cm}^{-1}$ [dT(C=O)], characterizing genomic DNAs from different in vitro grown plant species ([12] and references therein).

It has been shown, that changes in the subpicosecond surface dynamics of molecular subgroups in genomic DNAs from leaf tissues, can be monitored with surface-enhanced Raman spectroscopy.

The study of vibrational total half bandwidths of genomic DNA from leaf tissues, revealed a sensitivity of FWHM to the source of nucleic acid. Moreover, this proved to be dependent on the vibration under study. The SERS total half bandwidths of genomic DNA vibrations revealed a dynamic picture on a subpicosecond time scale [9].

In our study, the full widths at half-maximum (FWHMs) of the SERS bands in genomic DNAs from different leaf tissues, are typically in the wavenumber range from 15 to $30 \mathrm{~cm}^{-1}$ for data set 1 and from 13 to $42 \mathrm{~cm}^{-1}$ for data set 2 . Besides, the total half bandwidths in the SERS spectra are sensitive to a dynamics active on time scales from 0.35 to $0.71 \mathrm{ps}$ for data set 1 , and also from 0.25 to $0.82 \mathrm{ps}$ for data set 2 , respectively.

We have found that the bands of DNA from Florina cultivar and Kalanchoe leaves, respectively, are suitable for studying the dynamical behaviour of molecular subgroups in nucleic acids extracted from leaf tissues.

A comparison between different ranges of the Raman band parameters of plant genomic DNA, in the case of aqueous solution dynamics (investigated by FT-Raman spectroscopy) and surface dynamics (investigated by SERS) has also been given $[8,9]$.

\section{Acknowledgements}

The authors wish to thank to Dr. Adela Halmagyi and to Dr. Sergiu Valimareanu from the Institute of Biological Research, Cluj-Napoca, Romania, for preparation of genomic DNAs from different leaf tissues. 


\section{References}

[1] A. Hernanz, I. Bratu and R. Navarro, J. Phys. Chem. B 108(7) (2004), 2438-2444.

[2] T. Iliescu, S. Aştilean, I. Bratu, R. Grecu and D. Maniu, J. Chem. Soc. Faraday Trans. 92 (1996), 175-178.

[3] T. Iliescu, I. Bratu, R. Grecu, T. Veres and D. Maniu, J. Raman Spectrosc. 25 (1994), 403-407.

[4] V. Kozich, Ł. Szyc, E.T.J. Nibbering, W. Werncke and T. Elsaesser, Chem. Phys. Lett. 473 (2009), 171-175.

[5] C.M. Muntean and I. Bratu, Spectrosc. - Int. J. 21(4) (2007), 193-204.

[6] C.M. Muntean and I. Bratu, Spectrosc. - Int. J. 22(5) (2008), 345-359.

[7] C.M. Muntean and I. Bratu, Spectrosc. - Int. J. 22(6) (2008), 475-489.

[8] C.M. Muntean and I. Bratu, Spectrosc. - Int. J. 23(5,6) (2009), 281-289.

[9] C.M. Muntean, I. Bratu, N. Leopold and M.A.P. Purcaru, Spectrosc. - Int. J. 26(1) (2011), 59-68.

[10] C.M. Muntean, I. Bratu, K. Nalpantidis and M.A.P. Purcaru, Spectrosc. - Int. J. 23(3,4) (2009), 141-154.

[11] C.M. Muntean, N. Leopold, A. Halmagyi and S. Valimareanu, Spectrosc. - Int. J. 25(1) (2011), 33-43.

[12] C.M. Muntean, N. Leopold, A. Halmagyi and S. Valimareanu, J. Raman Spectrosc. 42(11) (2011), 1925-1931.

[13] C.M. Muntean, R. Misselwitz, L. Dostál and H. Welfle, Spectrosc. - Int. J. 20(1) (2006), 29-35.

[14] C.M. Muntean, R. Misselwitz and H. Welfle, Spectrosc. - Int. J. 20(5,6) (2006), 261-268.

[15] C. Otto, P.A. Terpstra, G.M.J. Segers-Nolten and J. Greve, in: Spectroscopy of Biological Molecules, J.C. Merlin et al., eds, Kluwer Academic, Dordrecht, 1995, pp. 313-314.

[16] A.V. Rakov, Optika Spektrosk. 7 (1959), 202-208.

[17] P.A. Terpstra, C. Otto and J. Greve, Biopolymers 41(7) (1997), 751-763. 


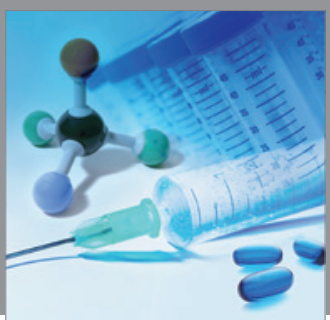

International Journal of

Medicinal Chemistry

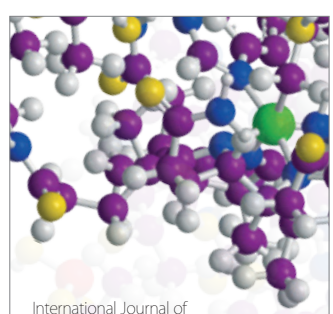

Carbohydrate Chemistry

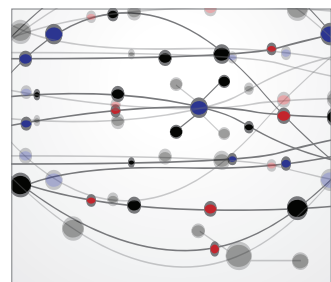

The Scientific World Journal
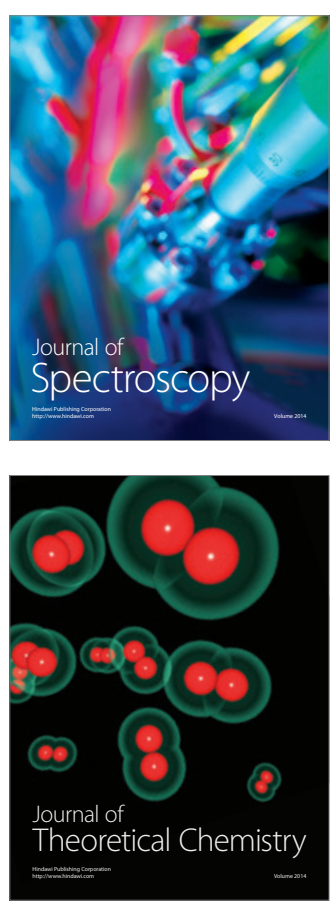
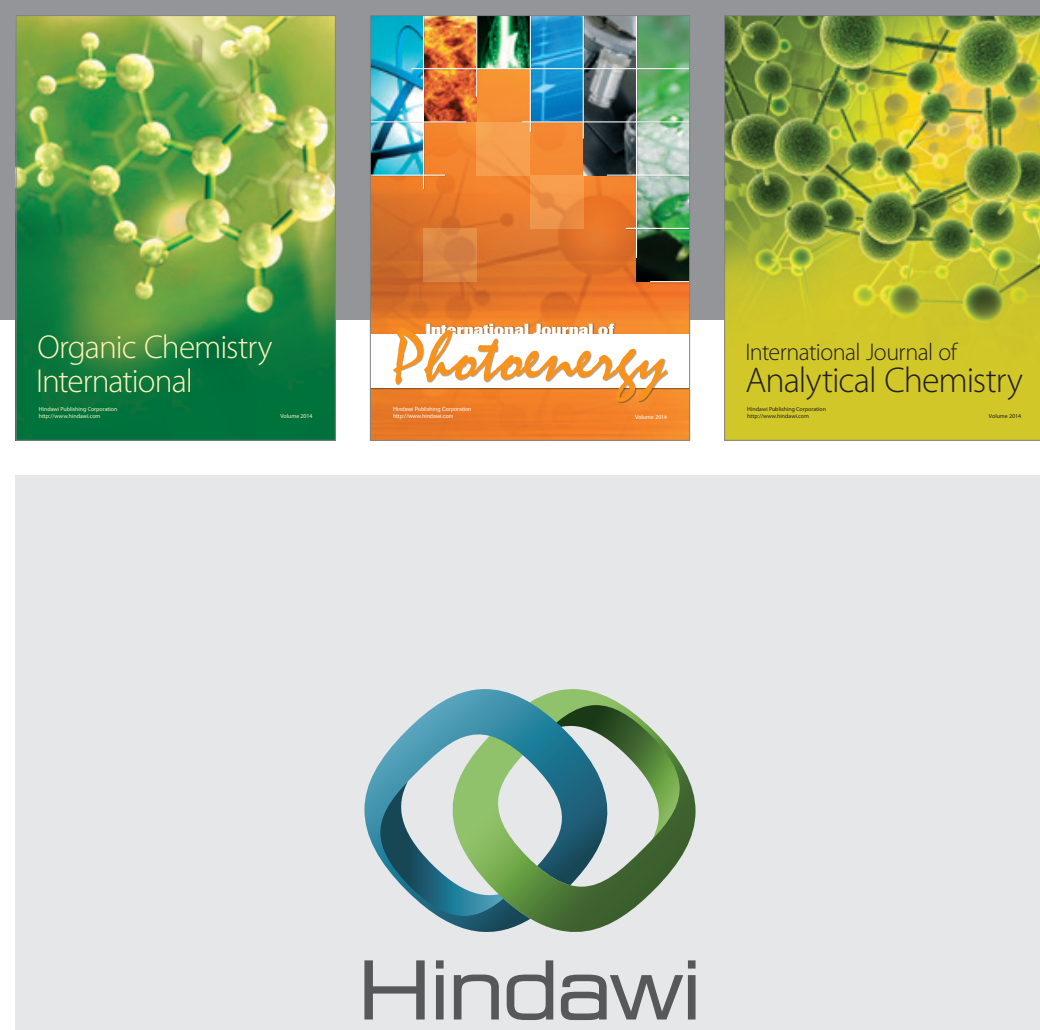

Submit your manuscripts at

http://www.hindawi.com
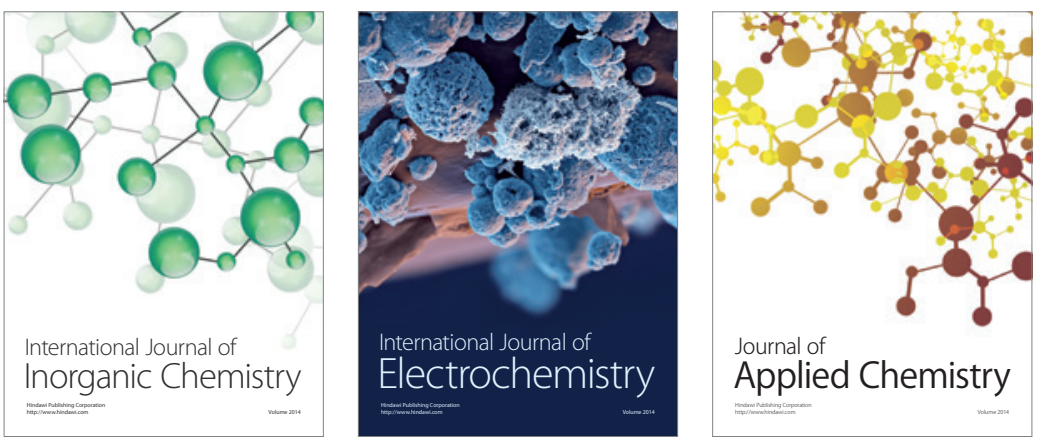

Journal of

Applied Chemistry
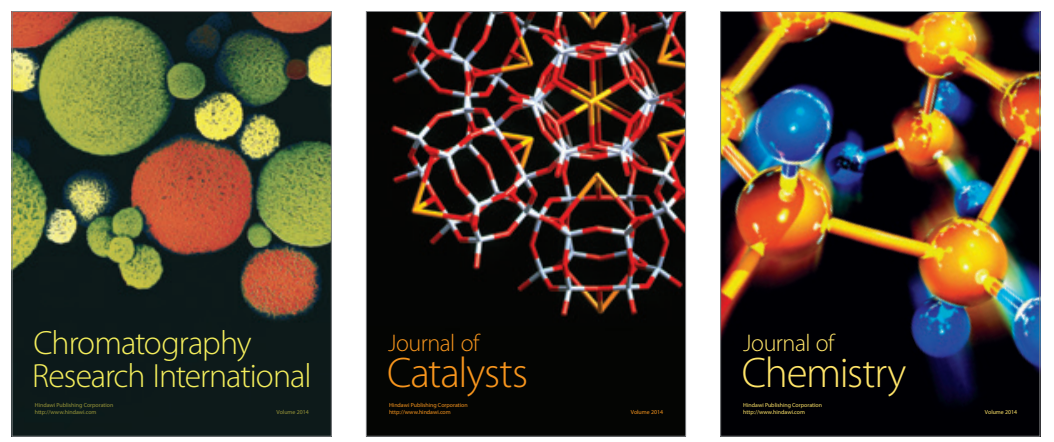
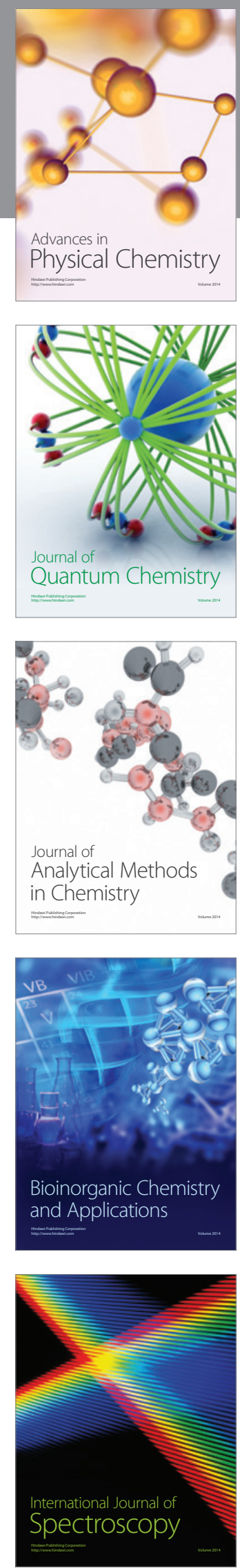